ÚlTIMA DÉCADA, N47, DICIEMBRE 2017, PP. 222-242

\title{
MÚSICA DE FESTA, EXPRESSÕES E SENTIDOS DO KUDURO NA CIDADE DE SALVADOR
}

\author{
FRANK MARCON $^{1}$ \\ ELY DAISY DE JESUS SANTOS ${ }^{2}$
}

\begin{abstract}
RESUMO
O kuduro é um estilo de dança e música eletrônica produzida e consumida principalmente por jovens, que surgiu em Luanda, nos anos 90 e aos poucos se espalhou pela Europa, América e África. Neste artigo analisamos a presença do estilo no Brasil, a partir dos jornais impressos, e analisamos o caso específico da sua produção, circulação e consumo através de pesquisa de campo que realizamos na cidade de Salvador - Brasil. A partir daí buscamos compreender o contexto festivo em que o estilo está inserido e refletir sobre os significados particulares e gerais de sua expressão em um circuito de consumo peculiar com a presença de jovens imigrantes africanos em contraponto com os sentidos mais amplamente difundidos. Esta pesquisa foi realizada no ano de 2014 e 2015 e é parte de um projeto mais amplo de investigações desenvolvido pelos autores sobre juventudes, processos de identificação e suas diferentes formas de expressão através de estilos de vida associado à música eletrônica.
\end{abstract}

PALAVRAS CHAVES: MÚSICA DE FESTA; KUDURO; ESTILO DE VIDA; JUVENTUDES;

$$
\text { DIÁSPORA }
$$

${ }^{1}$ Doutor em Antropologia Social. Professor do Departamento de Ciências Sociais da Universidade Federal de Sergipe, coordenador do Grupo de Estudos Culturais, Identidades e Relações Interétnicas (GERTS). Principal publicação: MARCON, Frank. Diálogos Transatlânticos: identidade e nação entre Brasil e Angola. Letras Contemporâneas: Florianópolis, 2005. Endereço Av. Des. João Bosco A. Lima, 700. Apto. 304. Aracaju/SE CEP 49037130 (Telefone 79 21056792). Correio eletrônico: marconfrank@hotmail.com

${ }^{2}$ Aluna do curso de Comunicação, da Universidade Federal de Sergipe, bolsista de IC/CNPq entre julho de 2013 e junho de 2015, no projeto Música e Estilos de Vida de Jovens no Brasil, Angola e Portugal: análise comparativa entre práticas e retóricas de identificação e diferença. Endereço Av. Des. João Bosco A. Lima, 700. Apto. 304. Aracaju/SE CEP 49037130 (Telefone 79 21056792). Correio eletrônico: ely.daisy@hotmail.com. 


\title{
MÚSICA DE FIESTA, EXPRESIONES Y SENTIDOS DEL KUDURO EN LA CIUDAD DE SALVADOR
}

\begin{abstract}
RESUMEN
El kuduro es un estilo de danza y música electrónica producida y consumida principalmente por jóvenes, que surgió en Luanda, en los años 90 y que al poco tiempo se difundió por Europa, América y África. En este artículo analizamos la presencia del estilo en Brasil, a partir de los periódicos impresos, y analizamos el caso específico de su producción, circulación y consumo a través de una investigación de campo que realizamos en la ciudad de Salvador - Brasil. A partir de ahí, buscamos comprender el contexto festivo en el que el estilo está inserto y reflexionar sobre los significados particulares y generales de su expresión en un circuito de consumo peculiar con la presencia de jóvenes inmigrantes africanos en contraste con los sentidos más ampliamente difundidos. Esta investigación se realizó en el año 2014 y 2015 y es parte de un proyecto más amplio de investigación desarrollado por los autores sobre juventudes, procesos de identificación y sus diferentes formas de expresión a través de estilos de vida asociados a la música electrónica.
\end{abstract}

PALABRAS ClAVE: MÚSICA DE FIESTA; KUdURO: ESTILO DE VIDA; JUVENTUDES; DIÁSPORA

\section{DANCE MUSIC, EXPRESSIONS AND MEANINGS OF KUDURO IN SALVADOR}

\begin{abstract}
Kuduro is a dance and electronic music style born and consumed mainly by young people born in Luanda in the 90s and quickly widespread to Europe, America and Africa. The present article focuses on the presence of kuduro in Brazil on the newspapers, analyzing the particular case of its production, spread and consumption through a field research carried out in Salvador, Brazil between 2014 and 2015. From here, we aim at gaining understanding of the festive atmosphere of this style and reflecting on both the general and particular meanings of this artistic expression in a particular consumption circuit (with African young immigrants), and in a more general meaning. This investigation is a part of a wider research developed by the authors about youths, identity processes and their different ways of expression through electronic music-related lifestyles.
\end{abstract}

KEYWORDS: PARTY MUSIC; KUDURO; LIFESTYLE, YOUTH; DIASPORA. 


\section{INTRODUÇÃo}

O kuduro surgiu mais precisamente em Angola, em Luanda, em meados dos anos noventa, através da junção da coreografia de passos de dança criada pelo dançarino Tony Amado, mais a forma de expressão musical da periferia oriunda das batidas eletrônicas mixadas em computadores, chegando às discotecas e as rádios de Luanda. Foi denominado kuduro por ser dançado com as nádegas contraídas. O estilo surgiu quando se encontraram determinada forma de dançar e de fazer música, se transformando num símbolo estético amplamente difundido em Angola. O que se deu pela progressiva facilitação do acesso às tecnologias de computadores, de captação de som e de imagem, mais a progressiva melhoria de acesso à internet, com a ampliação da comunicação rápida e a aquisição de informações, programas de mixagem e novos acervos de beats.

Em Luanda, os grupos de kuduro surgiram desta junção de jovens dançarinos, MCs e DJs. Sua produção musical era e continua sendo feita eletronicamente, na maior parte sem a mediação da indústria fonográfica de larga escala. As batidas são produzidas exclusivamente através da tecnologia digital, que em seguida ganham a voz dos MCs em estúdios muitas vezes improvisados. Os dançarinos exercitam uma infinidade de movimentos das articulações e realizam com elasticidade uma série de passos e acrobacias, com expressões faciais e corporais provocativas, enfatizando certa virilidade, certa sátira e certo erotismo. Em alguns contextos, os grupos de kuduro disputam hegemonias em regiões e bairros da cidade, sendo em alguns momentos associados às gangues de jovens e à marginalidade social. De qualquer modo, na última década, o estilo foi se tornando símbolo nacional em Angola e mais recentemente também ganhou este status social nos movimentos da diáspora angolana e africana. 
Com o processo migratório para o continente europeu e americano, que se ampliou nos primeiros anos do século XXI, o estilo foi se espalhando juntamente com a mobilidade dos jovens que ouviam o kuduro feito em Angola através de CDs que carregavam consigo, mas também por se manterem atualizados com relação às novidades através de contatos com parentes e amigos pela internet. Em Portugal, por exemplo, com algumas dezenas de milhares de angolanos residindo em bairros periféricos junto com outros jovens oriundos de Países Africanos de Língua Oficial Portuguesa (PALOPs), o kuduro se tornou uma expressão de socialização desta juventude. Há pouco mais de uma década, através da música e da dança freestyle, começaram a surgir os primeiros grupos de dançarinos, produtores e MCs de kuduro em Lisboa, formados por caboverdeanos, guineenses, sãotomenses, angolanos e portugueses. Aos poucos o estilo saiu da periferia para as pistas de dança de discotecas de música africana, foi se tornando conhecido nos programas de rádio e $\mathrm{TV}$, também alcançando algum reconhecimento como estilo de música eletrônica, num cenário em que o Estado e a mídia portuguesa passaram a se apropriar deste estilo denominando-o de nova música lusófona.

No Brasil, o caso particularmente analisado aqui, a imigração angolana não atingiu nem de longe os mesmos números que para Portugal (dados aproximados apontam para 6.000 angolanos residindo de forma permanente no país), embora o fluxo e a mobilidade de brasileiros e de angolanos de um lado para o outro dos dois países seja algo a se levar em consideração, mas difícil de mensurar seu volume para que possamos ter ideia precisa deste movimento. Estudos, trabalho, serviços de infraestrutura e comércio estimulam o movimento das pessoas, bem como o fato de haver famílias divididas entre os dois países são suposições que apontam para a possibilidade de números bem maiores. De qualquer modo, importa ressaltar que tais movimentos fizeram e fazem circular símbolos culturais e sonoros como o kuduro, o semba, a kizomba, entre outros, além da forte referência a uma ideia de diáspora africana alimentando o imaginário nacional e dos "movimentos sociais negros” no 
Brasil, que reivindicam laços históricos culturais comuns provenientes da memória sobre o escravismo.

Pelo menos nos últimos sete anos, interesses brasileiros no investimento em Angola, inclusive no mercado de comunicação, com a presença de TVs brasileiras no País, trouxeram as primeiras apresentações televisivas de kuduro ao Brasil, por volta de $2008,{ }^{3}$ embora existam registros de que os estudantes angolanos em universidades de grandes cidades brasileiras, já tivessem trazido seus acervos musicais e a dança do kuduro para as denominadas "festas africanas”, que eles próprios realizavam juntando-se aos estudantes africanos de outros países. Outro ponto de divulgação do estilo no Brasil, pelo menos a partir de 2005, foi quando Dog Murras (um dos primeiros artistas a relacionar o kuduro diretamente aos símbolos nacionais de Angola) passou a se apresentar todos os anos no carnaval na cidade de Salvador (um dos mais famosos do Brasil), a convite de alguns grupos baianos de trios elétricos.

Mesmo que limitado a alguns circuitos de audiência, práticas e representações, hoje existem grupos de kuduro no Brasil, circunscritos aos locais de imigração angolana, embora num contexto social diferente do que aconteceu e continua acontecendo em Angola ou em Portugal. No Brasil, alguns dados iniciais de nossa pesquisa demonstram que a relação com o kuduro está mais voltada para a experiência com a dança, com a plasticidade dos movimentos, do que propriamente com a música, através do enfoque no desejo de aproximação com algo que simbolize idealizadamente a cultura africana, ou mais especificamente a cultura angolana como parte desta.

Os cenários de expressão privilegiados do kuduro em Salvador, por exemplo, são os ambientes de festas produzidas com a finalidade de reunir pessoas em torno do que se considera um estilo ou gosto compartilhado por

${ }^{3}$ Quadro do programa "Hoje em Dia” exibido pela TV Record, que consistia num concurso em que jovens se inscreviam para dançar "kuduro". Houve uma grande participação de pessoas, embora muitos declarassem ter contato pela primeira vez com tal música ou dança.Ver, por exemplo: https://www.youtube.com/watch?v=rAX0xa3Wleo 
alguns jovens com trajetórias de vida peculiares, embora no encontro das festas eles compartilhem experiências e gostos comuns relacionados ao que consideram como música e dança “africana”.

Antes de adentrar na descrição de tais jovens e estilos, gostaríamos de destacar que falamos a partir da perspectiva de Paul Gilroy (2001) sobre os fluxos de pessoas, de discursos e da própria expressão sonora e estética em contextos de trânsitos, pensando num campo de conexões, experiências e entendimentos intercambiados em torno do que o autor denominou de Atlântico Negro. Procuramos, neste caso específico, observar e entender a presença do kuduro no Brasil a partir de Salvador, sem perder de vista as interconexões com os movimentos que nos levem para além da análise localizada, lembrando também a crítica de James Clifford, em Routes, ao apontar para uma antropologia sobre os encontros e os movimentos.

Assim sendo, nossos questionamentos são sobre como o kuduro se movimenta e significa no Brasil? Quais as motivações dos sujeitos que se envolvem como produtores e consumidores do estilo? Que sociabilidades e relações de poder estão ou podem ser aí evidenciadas? Que implicações geracionais e étnicas estão agregadas aos gostos e aos estilos do fazer e de consumir o kuduro? Que sentidos estão aí sendo disputados num cenário de mobilidades que ressignificam as identidades a todo instante?

\section{OS SENTIDOS MIDIATIZADOS DO KUDURO NO BRASIL}

Com o objetivo de elaborar alguma compreensão sobre a presença e as disputas pelos significados do kuduro no Brasil recorremos ao levantamento de jornais de três das maiores capitais brasileiras: Rio de Janeiro, Salvador e São Paulo. A intenção era perceber em que situações a referência ao kuduro 
aparecia nas notícias destes jornais entre os anos de 2008 e 2013 e quais eram os entendimentos que tais aparições suscitavam sobre o assunto.

$\mathrm{Na}$ grande maioria dos casos, as notícias foram veiculadas nos cadernos culturais ou de entretenimento dos jornais pesquisados. Em todas as cidades em questão, os jornais trataram o kuduro como “música angolana” ou "música africana”, às vezes associando-o a outros estilos caracterizados como de misturas eletrônicas, outras vezes associando-o aos estilos surgidos em contextos periféricos e apropriados por contextos festivos de música dançante, produzidos por DJs de uma cena considerada global.

Principalmente nas notícias sobre a cidade de São Paulo, o kuduro esteve associado aos festivais de música eletrônica e a um novo tipo de dança surgido das periferias das cidades africanas, alçadas ao cenário mais generalista de música eletrônica. Sobre o kuduro na cidade do Rio de Janeiro, por um lado, apareceram argumentos por alguma semelhança entre o kuduro e o funk carioca, apontado elementos sociais, de sonoridade e de plasticidade dos dois lados do Atlântico, e por outro lado apareceram algumas notícias associando o kuduro aos encontros festivos promovidos por imigrantes angolanos na cidade, ${ }^{4}$ como a seguinte notícia veiculada na Folha de São Paulo:

Kizomba, kuduro e semba africano misturados às batidas de funk animam os dias ensolarados dos freqüentadores do Piscinão de Ramos, vizinho à favela Roquete Pinto, no Complexo da Maré, maior conjunto de favelas do Rio com cerca de 130 mil habitantes, na zona norte. ${ }^{5}$

O significativo para reflexão que propomos é a ideia de aproximação e semelhança entre as expressões musicais contemporâneas da periferia do Rio de Janeiro e uma ideia de expressões musicais contemporâneas na África, bem

${ }^{4}$ Em depoimento na publicação da Revista IN (2012), do professor da Companhia Athletica Unidade Rio de Janeiro - Eduardo Neves, se referindo ao kuduro, afirma que: "os jovens imigrantes angolanos que vivem no Brasil são os grandes responsáveis pelo sucesso da dança. [...] Lembro que por volta de 1998 na Festa Soul que acontecia na Fundição Progresso, eles já dançavam de uma maneira diferente”.

${ }^{5}$ http://www1.folha.uol.com.br/cotidiano/2012/12/1194718-kuduro-agita-quiosques-deangolanos-em-piscinao.shtml 
como a ideia de que os ritmos periféricos se misturam por sua forma ou relações de proximidade cultural.

Nas notícias de jornais sobre a cidade de Salvador, foi possível percebermos argumentos sobre a existência de uma ideia de aproximação e cumplicidade com a descoberta do kuduro, principalmente quando os jornais começam a ressaltar que nos últimos anos este estilo foi incorporado a mais badalada das festas baianas, o carnaval, quase como uma consequência da própria dimensão de seu sucesso em Angola, Luanda, transposto para o Brasil, em Salvador.

É certo que nos últimos anos o estilo foi se tornando conhecido e caiu no gosto de algum público de diferentes regiões brasileiras, embora em cenas muito específicas de consumo e de sociabilidades. Cabe ressaltar, incluindo o entendimento de alguns DJs que entrevistamos em Salvador; como o DJ Elton, ${ }^{6}$ o DJ Fábio, ${ }^{7}$ o DJ Jolly ${ }^{8}$ e o DJ Raiz ${ }^{9}$, que o kuduro passou a compor uma estética de músicas para dançar em circuitos de festas que muitas vezes são denominadas por eles mesmos como "festas africanas" ou como "bailes de música preta” (blackmusic), na definição do DJ Raiz, embora longe dos cenários musicais hegemônicos no Brasil.

\section{Kuduro e Música Africana em Salvador}

Durante trabalho de campo realizado para esta pesquisa na cidade de Salvador/BA, percebemos que kuduro vem se propagando através de reuniões de determinados grupos de jovens presentes num mesmo espaço físico para se

\footnotetext{
${ }^{6}$ Entrevista realizada em Salvador, em 01 de julho de 2015, por Frank Marcon.

${ }^{7}$ Entrevista realizada em Salvador, em 14 de dezembro de 2014, por Ely Daisy de Jesus Santos e Frank Marcon.

${ }^{8}$ Entrevista realizada em Salvador, em 08 de março de 2015, por Frank Marcon.

${ }^{9}$ Entrevista realizada na data tal, em Salvador, em 14 de dezembro de 2014, por Ely Daisy de Jesus Santos e Frank Marcon.
} 
divertirem em festas e bailes de música. São situações de uma cena musical em que o objetivo é interagir através de um contexto de sociabilidades que perpassam o ato de dançar e de se estar juntos em torno de ritmos considerados "africanos", não havendo uma festa em que o kuduro reine em absoluto, mas festas em que este estilo se torna uma referência da ideia mais geral de um modo africano de dançar e festejar, com batidas musicais eletrônicas, forte expressão corporal e um contexto de socialização sensível pelas referências do gosto à procedência da música.

Recordamos que a socióloga Sarah Thornton (1996) propõe uma análise interessante sobre a relação entre música, dança e estilo de vida que inclui também a experiência social. Neste caso, consideramos aqui a dança como uma faceta social das festas fechadas que movimentam a motivação pela qual a música é produzida e pela qual é consumida, envolvendo os produtores e os frequentadores das festas. Thorthon (1996) sugere que devemos pensar sobre como as pessoas vivenciam as suas experiências em tais ambientes e eventos e como se expressam através de um dado gosto e um dado estilo de vida, mas também sobre quem são estas pessoas que as frequentam.

Aqui utilizamos a expressão "música de dançar" para buscar uma maior aproximação com o entendimento que fizemos no campo realizado sobre a circulação de uma estética musical associada à finalidade de sua utilização em contextos de audição coletiva em eventos festivos. Neste caso, as músicas são geralmente reproduzidas e mixadas com novos efeitos sonoros tecnológicos através da atuação dos DJs, com ampla repercussão estética sobre o uso dos corpos em performances dançantes, com volume alto, projeção de videoclipes e sob o efeito de jogos de luzes e sombras. A música aqui é um elemento importante que compõe este tipo de festa como evento dançante e como momento e lugar de encontro.

Em Salvador, por duas vezes estivemos na festa denominada "Baile Socakuduro", por outras duas vezes na festa denominada "Noite Africana” e, 
numa mesma ocasião, estivemos ainda na festa "Baile do Exalta Afro”. As festas são realizadas no período noturno, às sextas-feiras ou sábados e em diferentes lugares da cidade, concentrando-se nos bairros Campo Grande, no bairro da Barra e, principalmente, no boêmio bairro do Rio Vermelho, formando um circuito de festas do estilo, que são caracterizados por uma sazonalidade quinzenal. Os bairros mencionados são considerados áreas urbanas de oferta de atividades noturnas de lazer em Salvador, ligados ao consumo de distintos estilos musicais oferecidos por discotecas, restaurantes e bares, com ou sem pistas de dança.

Tais eventos e tais ambientes são parte do que estamos denominando aqui de “cultura da noite” em Salvador, a partir do mesmo entendimento de Mario Margulis (1994) para Buenos Aires, como aquela que é expressa numa temporalidade da vida das grandes cidades em que as práticas sociais se colocam no plano do lazer, do consumo e do festivo. Momento no qual as juventudes estão mais presentes em distintos circuitos marcados pelo gosto e pelo estilo. Margulis (1994) acrescenta que para os jovens a noite é o momento para encontrar espaços propícios, para integrar-se e diferenciar-se, ou seja, para também construírem-se espaços de identidade e diferença, a partir de eleições e restrições postas através de elementos simbólicos. O tipo de música, o poder econômico, a indumentária, a aparência e outros elementos estéticos e de poder podem definir tais proximidades ou distanciamentos com um tipo de festa, de pessoas ou de ambiente.

Ambientes festivos e musicais revelam formas de distinção social entre si e os DJs adquirem papel fundamental neste modelo de experiência festiva de distinção a partir da música. Propomos aqui pensar o gosto pelo kuduro e pela chamada “música africana” em Salvador, relacionando tal gosto com o produzir música para dançar, a partir da análise sobre como os sujeitos negociam os significados sociais do que dizem ter prazer de frequentar, ouvir, fazer e consumir. Ou seja, pensando o gosto como situado nas intersecções que 
definem a distinção social pelo estilo de vida que se assume, se estetiza e se politiza como diferenciação.

Para os DJ Fábio, DJ Joly e DJ Elton que produzem festas e shows em Salvador, o objetivo é trazer os ritmos dançantes que fazem sucesso em diferentes países da África, para atrair o público imigrante que vive na cidade, para que se sintam como se estivessem em casa, mas, ao mesmo tempo, com o intuito de que isto também possa atrair os "brasileiros" que gostam da "música africana”. Para os três DJs, o kuduro é um estilo dançante que sempre deve estar presente na lista das músicas tocadas, como parte do cenário das festas que eles realizam. São ritmos eletrônicos com a presença de toques de tambores digitalizados, em que o de batida mais acelerada e de sequências mais pulsantes é o kuduro, atingindo entre 139 a 149 batidas por minuto.

Fabio e Joly nasceram em Angola e Elton em Salvador, quando falam do que fazem, dizem que são DJs de “música eletrônica africana”. DJ Fábio produz e comanda a festa denominada "Noite Africana”, com a parceria de DJ Joly; enquanto DJ Elton criou o projeto “Afro Rave”. Todos afirmam que suas experiências musicais passam fortemente pelo kuduro, bem como ressaltam que fazem parte de uma cena musical maior que inclui outros ritmos também eletrônicos e a atuação como DJs em festas dançantes na cidade de Salvador, em que boa parte do público é formada por seus amigos e colegas. De modo bastante genérico, por vezes, eles denominam suas misturas como afrohouse ou afrobeat, dizendo que a característica destas é basicamente a velocidade menor com relação ao kuduro e uma sonoridade um pouco mais leve.

O evento "Baile Socakuduro", de acordo com sua própria página ${ }^{10}$ no Facebook $^{11}$ é realizado por um grupo de DJ's, com a liderança do DJ Raiz, que segundo ele, tem objetivo de reunir diversos grupos de jovens para uma experiência social com a música, procurando incentivar a dança em grupo, a

\footnotetext{
${ }^{10} \mathrm{https}: / /$ www.facebook.com/Socakuduro?fref=ts

${ }^{11}$ Rede social na internet que reúne pessoas aos seus amigos e contatos de trabalho, estudo e convívio.
} 
dois ou solo. O baile, segundo sua página de divulgação, também possibilita aos participantes aulas sobre ritmos africanos e ritmos denominados por ele como da diáspora africana. Manuela Casaldi, que produz a festa "Exalta Afro" também faz referência às aulas de kizomba e zouk, como parte do projeto que coordena. A proposta da dança está em todas as programações das festas aqui tratadas, seja espontaneamente, como lazer, ou também como forma de divulgação e aprendizado de estilos, como afirma o DJ Fábio sobre o seu objetivo em projetar videoclipes das músicas enquanto toca para, segundo ele, as pessoas se familiarizarem com o modo corporal de como as músicas são dançadas.

Segundo DJ Raiz, o kuduro é considerado uma das principais referências da festa ou do baile que realiza, mas o seu acervo musical passa também pelo ZoukBass, Ragga, Bahia Bass, Cumbia Eletrônica, Afrohouse, SocaMusic, Coupé-Decalé, Azonto, Tecno Brega, Funk Tamborzão (consciente), Funana, Hip Hop entre outros ritmos eletrônicos. Independente do ritmo, algumas das simbologias ressaltadas na divulgação da festa (cartazes e fotografias) são as imagens de pessoas dançando tais ritmos e o subtítulo da festa Socakuduro no material de divulgação carrega a expressão: "batida preta da diáspora”. A relação entre dança, corpo, batida e a referência a uma etnicidade afro/negra/preta a partir da música são elementos correlacionados na proposta destes eventos. 


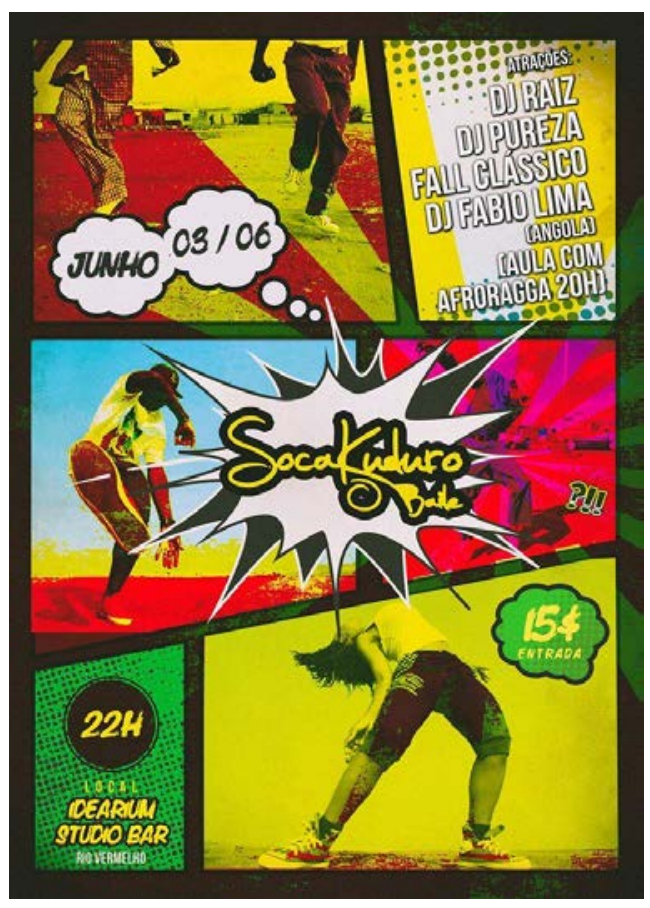

Fac Símile de Cartaz da festa Socakuduro, em 03/06/2015

Segundo o produtor do Socakuduro, o repertório da festa é fruto de pesquisa na internet sobre ritmos que tocam em diferentes países africanos e sobre a produção dos ritmos da diáspora africana surgidos no Caribe, na América e na Europa. O que, segundo ele, envolve muita troca de informações através das redes sociais e de compartilhamento de conteúdos sobre o que está em evidência em diferentes países, além da habilidade e da criatividade sobre os usos dos equipamentos de mídia e do uso do próprio acervo de música eletrônica na criação dos repertórios e da mixagem destinadas ao seu baile Socakuduro. O trabalho do DJ Raiz é performático e visa levar o público à pista de dança, à vibração e às afinidades com os ritmos do que ele considera serem as “batidas musicais contemporâneas da África e da diáspora”.

Para a reflexão que realizamos, cabe dizer que as ideias de “África” e de “diáspora” afirmadas pelos interlocutores são formas de expressar uma caracterização de um amplo cenário musical em que os DJs e o público 
imaginam estar conectados por alguma relação de proximidade sonora e cultural com uma África dispersa pelo mundo, como num sentimento de memórias e experiências coletivas. Neste caso, a “diáspora” como categoria nativa, utilizada pelo sugestivo nome dado ao baile pelo DJ Raiz, está aqui associada a um imaginário de conexões simbólicas relacionas e compartilhadas em alguma medida através da festa, da música e da dança. Tais características marcam uma referência de identificação com o estilo, com o significado acionado por todos que, ao atenderem ao chamado da festa Socakuduro, da Noite Africana, do Exalta Afro e do Afro Rave, compreendem os significados das palavras e a demarcação de um espaço próprio de socialização no cenário de consumo cultural de música em contextos jovens em Salvador, construindo um circuito próprio e marcando sua autenticidade e presença no território das expressões culturais da cidade.

Importante e mais complexo também é o fato de que a cidade de Salvador há décadas é divulgada para fora e para dentro do Brasil como cidade produtora de ritmos musicais de origem africana, o que caracterizou o surgimento do Axé Music, do Pagode Baiano e de outros estilos consagrados na grande mídia e nos grandes circuitos festivos como representativos de uma cidade de tradições e de cultura afro ou negra. Segundo os produtores e consumidores aqui em questão, este estilo de música considerado "baiano” não deve ser confundido com o circuito das "festas africanas” do qual tratamos até agora. ${ }^{12}$ Os públicos não são os mesmos e os DJs também procuram marcar uma distinção entre formas de fazer (digitalizadas) e estilos de tocar com referências contemporâneas da música urbana feita e consumida principalmente por jovens nos países africanos.

\footnotetext{
${ }^{12}$ Por mais que se reconheçam as possibilidades de mixagens que alguns deles têm realizado durante suas apresentações, bem como na produção de música, como na Angola e Bahia, em que recentemente o DJ Fábio misturou elementos do ritmo Axé Music com o Kuduro.
} 


\section{Produtores e Consumidores do Estilo}

Em entrevista realizada com DJ Raiz, ele diz que nasceu e sempre viveu em Salvador e que aos 15 anos começou a tocar junto com seu irmão, se interessando pela atuação como DJ em diferentes festas. Ele diz que sua formação musical é a discotecagem a partir do sound sistem e do dance hall e que já foi DJ de rap e de reggae. O seu projeto mais recente é o Socakuduro, que segundo ele tem o objetivo de reunir imigrantes africanos e as pessoas que gostam do ambiente da dança marcado pelos ritmos das batidas dos tambores, mesmo em suas versões digitalizadas e com o apelo à cultura urbana e periférica. Ele acrescenta que toda a pesquisa que faz é autodidata e boa parte se dá através da internet. Diz que conheceu o kuduro por volta do ano de 2008, começando a tocá-lo em algumas de suas festas e a partir daí não parou mais, acrescentando kizomba, semba, zouk e afrobeat.

Segundo Raiz, é aí que surge a justificativa para o slogan da festa que ele criou e que se conecta a ideia de diáspora, de "batida preta” ao que ele denominada de “música periférica”. Ou seja, “música preta”, da diáspora em situação periférica. Sobre o termo "música preta”, DJ Raiz diz: “Eu entendo como no Brasil a galera acabou assumindo a palavra "negro", mas acho que é bom ter essa reeducação da expressão, de negro ser preto mesmo. Porque o nome é forte, é carregado.” (DJ Raiz, 2014). O que significa que ele está levando em consideração a discussão no Brasil sobre a aceitação destas palavras como conceitos ou como referência de mobilização estética e política. Isto é polêmico, pois segundo ele, a palavra “preta” pode ainda não ser muito bem recebida para muitos, embora acima de tais diferenças entre o uso político adequado, a ideia, segundo ele, é pensar a música e fazer uma festa que misture estilos caribenhos com africanos, sempre seguindo a direção de uma experiência maior que a própria África. 
De acordo com DJ Raiz, o público de suas festas é sempre diversificado, vai de universitários às pessoas na faixa dos 50 anos. Para ele público é formado por pelo menos $50 \%$ de imigrantes africanos e a outra metade é de pessoas como amigos, admiradores e curiosos sobre a proposta.

Numa das oportunidades em que estivemos no campo, percebemos que muitas pessoas se reconhecem e se juntam para conversar ou estão em grupos ou pares para dançar, demonstrando certa familiaridade entre a maioria dos presentes. Percebemos que algumas vezes nossa presença causava estranhamento entre os frequentadores e um deles nos vendo com a máquina fotográfica em certa ocasião interpelou com a expressão “Tiozão, tira uma foto da gente aí”. Uma marca de estranhamento notadamente geracional e provavelmente indicando outros signos sociais de diferenciação, como o que também apareceu numa outra ocasião, na III Noite Africana, quando fomos interpelados por um jovem nascido em Cabo Verde e que recém concluíra o curso universitário em Salvador, com a pergunta: "Você é da TV? Esta fazendo a cobertura da festa?” Tais critérios de distinção demonstram como parte significativa do público é sensível aos marcadores sociais que definem “os de dentro" e "os de fora” deste circuito festivo e como isto tem relação com a indumentária, o fenótipo, a faixa etária e o comportamento na festa.

O público é bastante ativo e quase sempre se repete. Uma característica também importante da Noite Africana é que o ambiente é decorado com panos estampados e coloridos trazidos da África e que junto à porta de entrada da festa são estendidas bandeiras de países como Angola, Cabo Verde e Guiné Bissau, entre outras. Algumas vezes os próprios frequentadores trazem suas bandeiras fazendo referência ao País de origem. Também são projetados na parede imagens de várias partes da África, bandeiras de países africanos ou videoclipes de festas e de músicas que o público reconhece. A forma de dançar também é muito característica, enquanto as músicas de batida mais rápida são dançadas em passos solos com grande agitação de pernas e ombros, as músicas 
de batidas mais lentas são dançadas em pares com os corpos colados e em movimentos rápidos de quadril e pernas, o que nossos interlocutores ressaltaram ser uma característica da forma de dançar nas "festas africanas", com as quais os "brasileiros” não estariam tão acostumados.

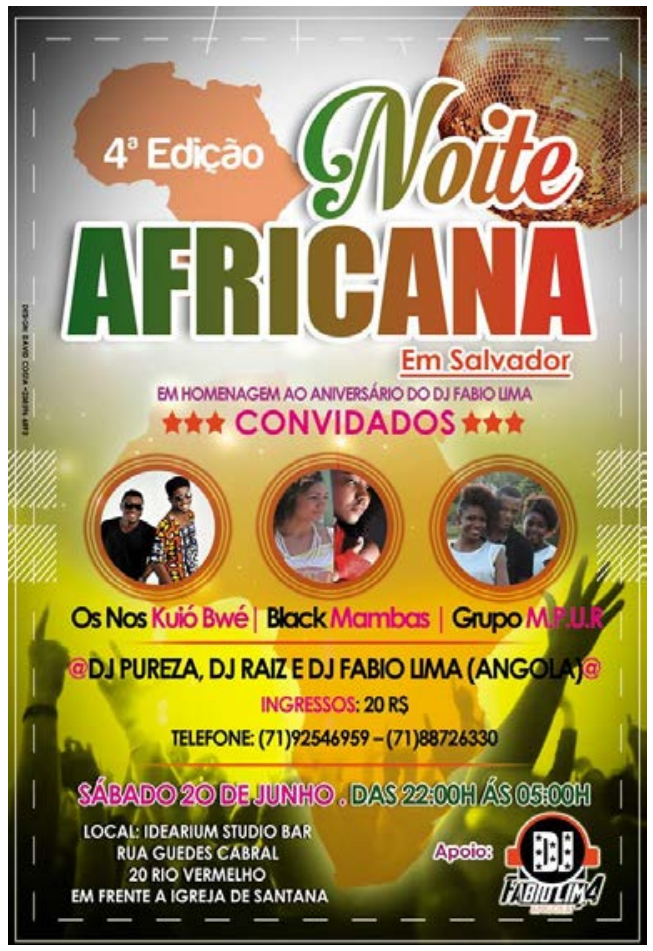

Fac Símile de Cartaz da Noite África, de 20 de junho de 2015

Criador da Noite Africana, DJ Fábio veio de Luanda para Salvador com mais nove amigos para estudar. Quando o entrevistamos pela primeira vez já estava atuando como DJ, embora concluindo sua faculdade de Arquitetura. Segundo ele, depois de transitar por algumas festas brasileiras, diz ter sentido a necessidade de trazer um ritmo diferente para a cidade. Conta que quando vivia em Angola teve algumas experiências tocando em festas e quando chegou a Salvador ficou alojado próximo ao Rio Vermelho, onde segundo ele o agito noturno é grande e já existiam festas com ritmos africanos. Então ele resolveu 
aos poucos aprender a mexer em equipamentos mais profissionais e investir na sua carreira como DJ, trazendo ritmos “angolanos” para as festas em Salvador. Segundo ele, existe uma leva de jovens oriundos de Angola, Cabo Verde, Guiné-Bissau e de outros países africanos que chegam ao Brasil, neste caso específico em Salvador, em busca de estudo e trabalho, mas também vivem suas vidas em função de sociabilidades e de lazer, surgindo daí reuniões festivas entre eles, algumas delas realizadas em suas próprias casas, na casa de amigos ou na Casa de Angola. ${ }^{13}$

Foi assim que DJ Fábio começou, em reuniões de amigos, depois sendo convidado para festas em bares e discotecas e depois produzindo a Noite Africana. Sobre os estilos musicais diz que toca desde o kuduro, passando pelo semba, funaná, coladeira, afrohouse, afrodance e afrobeat. Embora afirme que o kuduro é o seu ritmo preferido. Recentemente começou a arriscar composições e fez um kuduro que se chama “Angola e Bahia”, em que, segundo ele, o intuito foi misturar sua “relação com Angola e Bahia (DJ Fábio, 2014). Deste modo ele idealizou uma mistura entre a batida do kuduro e a presença da guitarra eletrônica para dar um impacto que para ele é típico do “carnaval baiano”. A estrofe da música diz: “Nossa Angola, cuia, cuia que cuia... A Bahia cuia, cuia, cuia que cuia... Isso é Angola e Bahia, Angola e Bahia... Isso é Angola e Bahia...” (DJ Fábio, 2014), e a letra segue comparando semelhanças e diferenças entre Angola e Bahia.

São trajetórias pessoais e projetos como estes que falam a partir de uma ideia de periferia e de África no Brasil, que evidenciam experiências de agência com a música num cenário de visibilidade e ao mesmo tempo de efemeridade possibilitados pela música digital e expressos coletivamente através da dança. Imigrantes africanos, temporários ou permanentes, produtores culturais e pesquisadores de música, promotores de movimentos culturais ligados à

\footnotetext{
${ }^{13}$ Centro cultural constituído por iniciativa da Embaixada de Angola no Brasil, com apoio do
} Governo da Bahia e de capital privado, ver: http://www.casadeangolanabahia.com.br/ 
música, à dança e à cultura contemporânea definida como africana, recolocam o debate e os significados sobre a África no Brasil, criando um cenário de aproximação e distanciamento em que as identidades e as diferenças se tornam uma seara de múltiplas ambivalências.

De modo contundente os imigrantes vindos de países da África subsaariana para o Brasil passam a definir seus lugares e suas formas de intervenção e afirmação coletivas também a partir do lazer, do estilo e do gosto que compartilham juntos por um modo de ser "africano" (ou angolano, guineense, cabo-verdiano, etc.), através da música, da dança e da festa. Tais festas são caracterizadas por agregar tais imigrantes, embora entre eles também surjam marcas nacionais de diferenciação e a partir daí outras questões que poderão ser analisadas em outras oportunidades.

\section{CONSIDERAÇÕES FINAIS}

A produção e o consumo de estilos reproduzidos digitalmente, que se proliferam à medida que colaboram mais ou menos com os circuitos de festas, têm promovido formas de socialização e reunião de jovens que partilham de gostos comuns baseados na música eletrônica e dançante reconhecida como africana, periférica e diaspórica. São jovens que partilham da cultura das festas, que se juntam em função dos gostos comuns, através da qual recuperam repertórios de memórias familiares ou suas próprias trajetórias de vida. Eles transformam o gosto pela música em sentimentos coletivos, reelaboram estéticas através do encontro amparado pelo elo comunicativo das festas dançantes, como uma referência importante da demarcação do que pensam e o do que sentem.

O kuduro é uma das expressões deste gosto que tem funcionado como significante de "música africana", de "música preta”, da "diáspora” ou da 
“periferia” entre os jovens imigrantes. Sua característica de produção independente, de facilidade de mobilidade pelo uso dos equipamentos eletrônicos, de rápido compartilhamento pela internet, caracteriza uma forma de interagir que está pautada por um modo de reconhecimento geracional de como fazê-lo, que dinamiza a socialização do gosto e do estilo também em situações adversas como as de imigração.

No contexto de Salvador observamos os surgimentos de circuitos de lazer que dão sentidos coletivos as sociabilidades entre jovens vindos de diferentes países do continente africano através da música e da festa. Outros significados de África passam a ser disputados, implicados, neste caso, pelas trajetórias das migrações contemporâneas, pelos sentimentos nacionais e étnicos que emergem de tais experiências de deslocamentos e pelas simbologias que afirmam a “diáspora africana” como uma forte referência de identificação negro-africana, ao tempo em que também se convertem socialmente em sentidos de distinção social, cultural e geracional no terreno destas experiências migratórias recentes.

Fora de Angola, o kuduro como ícone musical das festas, como as que aqui estão questão, se tornou um estilo agregador entre muitos jovens imigrados a partir dos países africanos, principalmente dos considerados Países Africanos de Língua Portuguesa (PALOPs). Talvez por isto, as dinâmicas na forma de produção, de circulação e de consumo próprias do kuduro passaram em muitos casos a ser o modo operativo de outras expressões musicais que se tornaram parte do setlists dos DJs das “festas africanas”.

Por fim, entendemos que o kuduro assume diferentes significados no Brasil, por um lado marcado por generalizações por parte da mídia e por outro se tornando signo importante das relações concretas de sociabilidades entre imigrantes oriundos da África. Estas sociabilidades se realizam em encontros festivos, em que a dança e a música se tornam expressões de gosto comum e de estilo compartilhado. As implicações mais evidentes de distinção social a partir 
deste estilo são as marcas etárias e étnicas, que por um lado remetem ao comportamento geracional de jovens estudantes, com acesso as mídias digitais e à internet, e por outro lado são etnicizadas pelas referências fenotípicas, pelos sotaques linguísticos, pela referência aos países de origem ou por aspectos simbólicos da expressão corporal.

A partir daí, percebemos que as "festas africanas" e seus símbolos sonoros como o kuduro não fazem parte das referências musicais hegemônicas em Salvador, nem dos circuitos das mais movimentadas festas noturnas e de lazer nos bares da cidade, apesar de presente na programação do carnaval, como menciona a notícia de jornal citada anteriormente. A idealização da África permanece ao mesmo tempo como representação de proximidade e distância a depender das circunstâncias demarcadoras da distinção social em Salvador (como na Bahia ou no Brasil), assim como o kuduro pode significar algo entre o familiar e o exótico a depender de quando, onde e porque é expresso, é produzido e é consumido.

\section{REFERENCIAS BIBLIOGRÁFICAS}

Gilroy, Paul. (2001). O Atlântico Negro. São Paulo: Ed. 34; Rio de Janeiro: Ed. UCAM

Margulis, Mario. (1994). "La cultura de la noche”. En Margulis, M. et al. La cultura de la noche: la vida nocturna de los jóvenes en Buenos Aires. Buenos Aires: Biblos.

Thornton, Sarah. (1996). Club Cultures: music, media and subcultural capital.Middetown, Connecticut:WesleyanUniversity Press.

Recepción de artículo: septiembre 2016

Fecha de aceptación: diciembre 2017 